\title{
Subjective Assessment of Stress and its Relationship with Neuroendocrine Mechanisms of its Development in Obstetricians- Gynecologists against the Background of Professional Burnout
}

\author{
Mikhail Yu. Kuzmin, PhD; Darya P. Tyumentseva; Maria A. Rashidova, PhD; \\ Leonid F. Sholokhov, PhD, ScD; Anait Yu. Marianian, PhD, ScD \\ Scientific Centre for Family Health and Human Reproduction Problems \\ Irkutsk, the Russian Federation
}

\begin{abstract}
The purpose of this case-control study was to investigate the factors of subjective assessment of stress and their relationship with neuroendocrine mechanisms of its development in obstetricians-gynecologists against the background of professional burnout.

Methods and Results: A total of 96 physicians and nurses from the different clinics specializing in both obstetrics and gynecology were surveyed. The Russian versions of MBI, BDI, SF-12, FFMQ, MAAS, and Coping strategies (the Ways of Coping Checklist) were applied. Blood serum/plasma was tested on the concentration of hormones (DHEA-C and TSH), melatonin, serotonin, and dopamine. Saliva cortisol was also estimated. In the present study, $43.75 \%$ of the physicians and nurses showed a high degree of burnout, which was comparable to that among physicians and nurses in other studies. Physicians and nurses with a high degree of burnout had more expressed coping strategies like Confrontive coping, Distancing, Self-controlling, Seeking social support and Escape-avoidance. Also, they have more expressed level of depressive manifestations. We found significant correlations between some factors of subjective assessment of stress (like coping and mindfulness) and neuroendocrine biomarkers. Adaptive coping like Planful problem-solving correlated negatively with the level of melatonin, and subscales of the mindfulness questionnaire were correlated negatively with levels of some biomarkers. Thus, we concluded that coping strategies and mindfulness could theoretically contribute to a decrease in the secretion of several hormones.

Conclusion: Physicians and nurses with a low degree of burnout have a greater level of mindfulness and a lower level of some maladaptive coping strategies - Confrontive coping, Distancing, Escape-avoidance. Our results focus on the predictive role of these factors of subjective assessment of stress, in particular, Confrontive coping and mindfulness, in burnout syndrome. The present data confirm that there are some psychological and physiological aspects related to stress in the medical profession. (International Journal of Biomedicine. 2021;11(4):551-557.)
\end{abstract}

Key Words: obstetricians-gynecologists $\bullet$ stress $\bullet$ professional burnout $\bullet$ biomarkers

For citation:Kuzmin MYu, Tyumentseva DP, Rashidova MA, Sholokhov LF, Marianian AYu. Subjective Assessment of Stress and its Relationship with Neuroendocrine Mechanisms of its Development in Obstetricians-Gynecologists against the Background of Professional Burnout. International Journal of Biomedicine. 2021;11(4):551-557. doi:10.21103/Article11(4)_OA25

\section{Introduction}

Burnout is a state of physical and emotional exhaustion, depersonalization, and a decreased sense of personal accomplishment caused by work-related stress. It is an outcome of chronic depletion of the individual's coping resources

*Corresponding author: Mikhail Yu. Kuzmin, PhD Scientific Centre for Family Health and Human Reproduction Problems, Irkutsk, the Russian Federation. E-mail.mirroy@mail.ru resulting from prolonged exposure to stress, particularly work-related stress. ${ }^{(1)}$

This problem is relevant for representatives of various professions, including medical workers. Its prevalence can be judged, for example, according to Rodrigues et al., ${ }^{(2)}$ who indicate that burnout is characteristic of workers in general surgery, anesthesiology, obstetrics/gynecology and orthopedics $-40.8 \%$; plastic surgery and pediatrics $-30.0 \%$; otolaryngology and neurology $-15.4 \%$.

The estimates of the prevalence of burnout in ObGyn vary widely but they remain high $-39 \%,{ }^{(3)} 50 \%,{ }^{(4)}$ and up to 
$75 \%{ }^{(5)}$ As a consequence of burnout, healthcare professionals may develop symptoms such as anxiety, irritability, mood swings, insomnia, depression, and a sense of failure. ${ }^{(6-8)}$

Some theoretical bases explain the relationship between stress as a psychological factor and exhaustion. Several studies in the medical area have analyzed the relationship between socio-demographic, occupational, and personality variables and the occurrence of burnout syndrome. The factors that prevent burnout are job satisfaction ${ }^{(3)}$ and self-efficacy. ${ }^{(9)}$ One of the strategies that can prevent burnout is the subjective assessment of stress, which is associated with personality variables such as extraversion, conscientiousness, and openness, ${ }^{(10)}$ coping strategies, and mindfulness. ${ }^{(11)}$ The most commonly used programs are mindfulness programs. ${ }^{(12-14)}$

Other studies have analyzed the relationship between psychological parameters of burnout symptoms and neuroendocrine mechanisms of stress. ${ }^{(15-20)}$ There are still many possible neuroendocrine mechanisms between burnout and stress that are being discussed. Since burnout is generally the result of a prolonged period of stress, it is often hypothesized that the hypothalamic-pituitary-adrenal (HPA) axis, a part of the neuroendocrine system involved in the regulation of stress reaction, may be disturbed in individuals suffering from burnout. Chronic exposure to stressors can contribute to permanent HPA axis activation. As the major output of the HPA axis is the stress hormone cortisol, cortisol levels are considered to be different among subjects with burnout than among healthy people. ${ }^{(15)} \mathrm{Also}$, chronic stress is associated with hyperstimulation of the hypothalamic-pituitary-thyroid (HPT) axis and related to thyroid function. Besides, the sympatheticadrenal-medullary axis stimulates adrenal glands to release catecholamine (eg, dopamine). It has been reported that the level of DHEA-S has been associated with burnout. ${ }^{(21)}$ Also, since the level of stress in obstetricians and gynecologists is closely related to night shifts, the level of their burnout may be related to the level of melatonin.

Some studies have shown how different biomarkers predict burnout. ${ }^{(15,12,22)}$ But in general, according to DanhofPont et al., ${ }^{(23)}$ no potential biomarkers for burnout can be found, largely due to the incomparability of different studies (study designs and methods, including the characters of patients, assess biomarkers and control for confounders). There is also a discussion of the context in which factors of subjective assessment of stress, like coping strategies and mindfulness, influence burnout. ${ }^{(11,24-26)}$

It has not been shown how these factors of subjective assessment of stress are connected with neuroendocrine mechanisms of stress that predict the development of burnout in obstetricians and gynecologists. In turn, the research into these factors and their relationship with stress biomarkers could contribute to the creation of a program to prevent burnout among physicians and nurses employed in obstetrics and gynecology.

Therefore, the purpose of this case-control study was to investigate the factors of subjective assessment of stress and their relationship with neuroendocrine mechanisms of its development in obstetricians-gynecologists against the background of professional burnout.

\section{Materials and Methods}

\section{$\underline{\text { Participants }}$}

We invited 181 people to participate in the study, 85 of whom were excluded because they did not meet inclusion criteria $(n=37)$ or declined to participate $(n=48)$. A total of 96 physicians and nurses from the different clinics specializing in both obstetrics and gynecology were surveyed. They were selected personally and in a consecutive manner by a researcher after contact with all of the professionals working on the units.

The inclusion criteria were as follows: fully completed questionnaires and the results of hormonal studies, age over 18 years. All participants were given a document about the objectives and procedures of the study.

\section{Instruments}

Symptoms of burnout were measured with the Russian version of the Maslach Burnout Inventory (MBI). ${ }^{(27)}$ This instrument is currently the most commonly used for evaluating burnout in healthcare professionals. The MBI consists of 22 elements. The MBI's three subscales were analyzed separately: Emotional exhaustion (EE), Depersonalization (DP), and Personal accomplishment (PA). Mean values were calculated and subscales were categorized into "low," "moderate," and "high" degrees of burnout using the cut-off values suggested by the Russian adaptation. ${ }^{(28)}$ For the EE subscale, this translates into $\leq 15,16-24$, and $\geq 25$ points, respectively; for the DP subscale - $\leq 5,6-10$ and $\geq 11$ points, respectively; and for the PA subscale - $\leq 30,37-31$, and $\geq 37$ points, respectively. Higher scores on the subscales EE and depersonalization indicate a higher degree of burnout, while a higher score on the subscale PA indicates a lower degree of burnout.

Coping strategies were measured with the Ways of Coping Checklist, Russian adaptation. ${ }^{(29)}$ The Russian version of this psychometric test consists of 50 questions and eight subscales - Confrontive coping, Distancing, Self-controlling, Seeking social support, Accepting responsibility, Escapeavoidance, Planful problem-solving, Positive reappraisal. Each answer was assigned from 0 to 3 points from "never" to "often." Coping strategies where the subject scored the highest score are considered to be leading.

We also used the 21-item Beck Depression Inventory (BDI) and SF-12 questionnaire (Russian version). ${ }^{(29)}$ The 21item BDI) measures depressive symptoms. This psychometric test consists of 21 questions regarding the subject's recent mood with each answer being assigned from 0 to 3 points. The SF-12 questionnaire is the short form of the SF-36 Health Survey, which measures adequate physical and mental health summary scores.

In addition, we used the Russian version of the Five Facet Mindfulness Questionnaire - $\mathrm{FFMQ}^{(30)}$ and Mindful Attention Awareness Scale, MAAS. ${ }^{(31)}$ The first questionnaire consists of 39 statements with a choice of assessment on a 5-point Likert scale from "never or very rarely true" to "very often or almost always true." It includes five factors: Describe (name, ability to turn one's emotions, sensations, thoughts into words), Non-judging of inner experience, Non-reactivity to inner experience, Act with awareness (concentration, 
action "not automatically"), Observe (attention to sensations, feelings, thoughts). The second questionnaire contains 15 statements. The gradation of answers from "almost always" to "almost never" is used.

The blood serum, blood plasma, and saliva were used as the biomaterials. Blood serum was tested on the concentration of hormones: DHEA-C and TSH using Alkor Biotest systems (Russia), melatonin using the ELISA Kit for Melatonin (CloudClone Corp., USA), and serotonin using Serotonin ELISA (IBL-International, Germany). Quantitative determination of plasma dopamine was measured using Dopamine ELISA(IBLInternational, Germany). Saliva cortisol was estimated using a Cortisol Saliva ELISA(DBC- Diagnostics Biochem Canada Inc.). Measurements were made using ELx808 ${ }^{\mathrm{TM}}$ Absorption Microplate Reader (BioTek Instruments, Inc., VT, USA).

\section{Procedures}

All participants were invited to the study on a voluntary basis. First, before the survey, the purpose of the research was clarified. The participants were instructed on how to fill out the questionnaires and informed that the survey would not have any influence on their work or personal life. Second, sociodemographic information was obtained by a researcher in order to determine whether they met the inclusion criteria. Third, participants signed the written informed consent form and completed the self-administered evaluation and all the abovementioned questionnaires. Fourth, participants gave saliva and blood. Before any therapy was prescribed, in the fasted state, from 8 a.m. to 9 a.m., after a 15 -minute rest, blood was sampled from a median cubital vein, using disposable vacuum blood collection tubes; $4-5 \mathrm{~mL}$ of saliva was collected into a clean special test tube (SaliCaps, IBL International $\mathrm{GmbH}$, Hamburg, Germany) without force or inducement and before eating, drinking, or brushing the teeth. Before sampling,, the mouth was simply rinsed out with water. All samples were then stored at $4^{\circ} \mathrm{C}$ until sent to the laboratory.

\section{Data Analysis}

All data have been entered into the REDCap system. ${ }^{(1)}$ Statistical analysis was performed using the IBM SPSS Statistics V23.0. The normality of distribution of continuous variables was tested by one-sample Kolmogorov-Smirnov test. Continuous variables with normal distribution were presented as mean (standard deviation $[\mathrm{SD}]$ ); non-normal variables were reported as median (interquartile range [IQR]). Means of 2 continuous normally distributed variables were compared by independent samples Student's t test. Mann-Whitney U test was used to compare means of 2 groups of variables not normally distributed. The frequencies of categorical variables were compared using Pearson's chi-squared test or Fisher's exact test, when appropriate. A multiple logistic regression model was made to identify predictive factors (independent variables) of burnout (dependent variables). The results are shown as odds ratios (OR.) with $95 \%$ confidence intervals $(95 \% \mathrm{CI})$ for $\operatorname{Exp}(\mathrm{B})$. The fit of the models was judged by the likelihood ratio test statistic. A probability value of $P<0.05$ was considered statistically significant.

The study was carried out in compliance with Ethical Principles for Medical Research Involving Human Subjects, Adopted by the 18th WMA General Assembly, Helsinki,
Finland, June 1964, and amended by the 64th WMA General Assembly, Fortaleza, Brazil, October 2013. The study was approved by the Ethics Committee of the Scientific Center for Family Health and Human Reproduction Problems. Written informed consent was obtained from each participant.

\section{Results}

The socio-demographic characteristics of the study sample are presented in Table 1.

Table.1.

Socio-demographic characteristics of the study sample

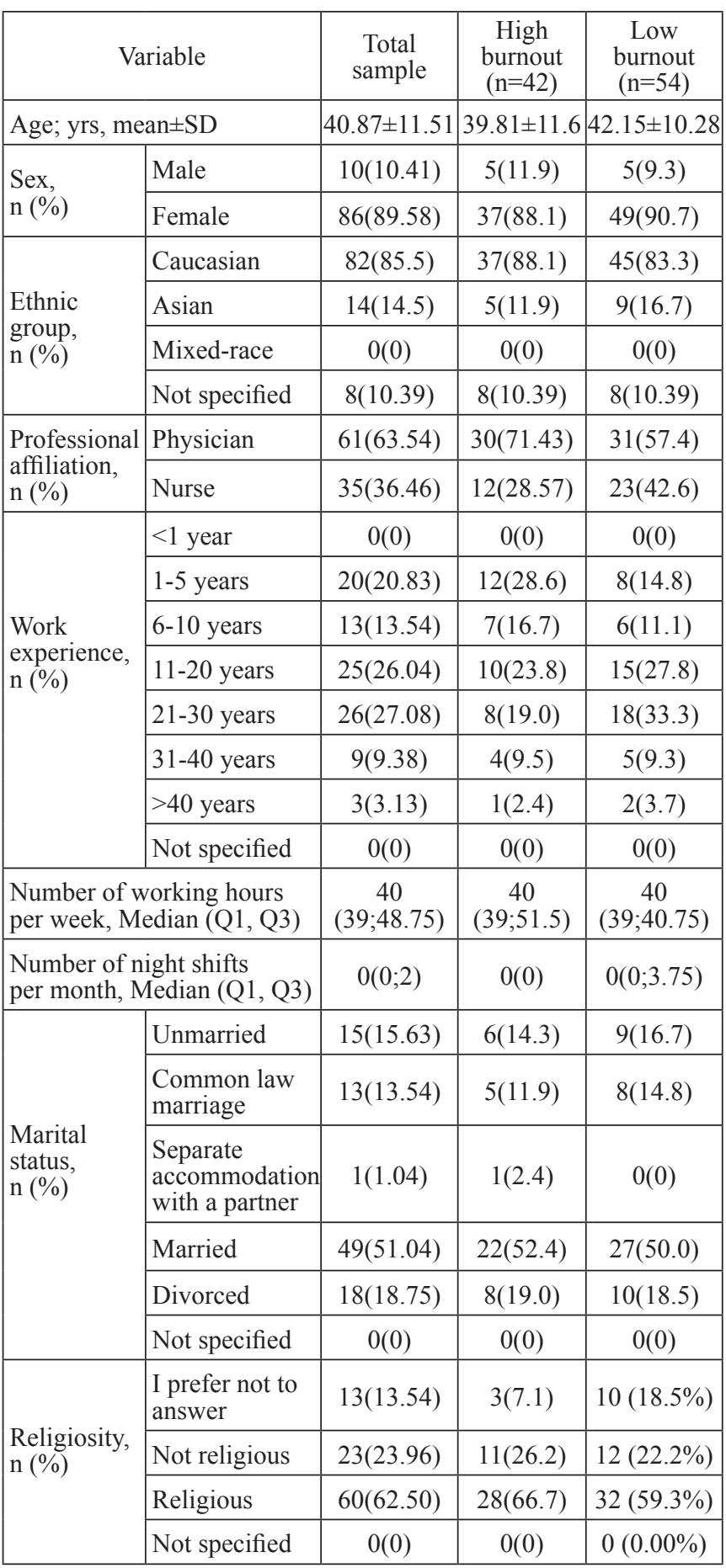


A total of 96 physicians and nurses of ObGyn were included in this study. Of these, $89.58 \%$ were women and $10.41 \%$ men, mostly Caucasian $(85.5 \%)$, married $(51.04 \%)$, and religious $(62.5 \%)$. The average age was $40.87 \pm 11.51$ years, with an age range of 22-69 years, and clinical work experience mean of $17.4 \pm 11.2$ years. About $30.2 \%$ of the physicians and nurses worked night shifts.

First of all, we found that in the sample, the EE subscale score was $25.33 \pm 11.22$. This value was high for this scale. The DP subscale score was $11.09 \pm 7.28$, which meant a high level of expression. Finally, the PA subscale score was $38.69 \pm 6.69$, which meant a high level of expression. Thus, subjects primarily exhibited high levels of EE and DP rather than professional reduction.

There are different criteria for diagnosing burnout. ${ }^{(15,20)}$ We use criteria from Deneva et al. ${ }^{(15)}$ with the amendment for the Russian version of the MBI. A diagnosis of burnout (yes/ no) was assigned if respondents presented high levels in at least two subscales (either EE and/or DP, associated or not with low PA) or in three subscales based on the following scores: $\mathrm{EE}>24$, DP $>10$, and $\mathrm{PA}<30$. According to this, $43.75 \%$ of the physicians and nurses indicated a higher degree of burnout and $56.25 \%$ had a lower degree of burnout.

We found that there were no significant differences in socio-demographic characteristics between physicians and nurses with a high degree of burnout and those without it (Table 1). No significant differences were found between physicians and nurses employed on night shifts and those not employed on them, or who have different family status and work experience, although these parameters are considered as burnout factors. ${ }^{(32)}$

In the next step, we found significant differences in psychological characteristics between physicians and nurses with a high degree of burnout and those without it (Table 2). We found statistically significant differences between studied groups: physicians and nurses with a high degree of burnout have more expressed coping strategies like Confrontive coping $(P=0.006)$, Distancing $(P=0.003)$, Self-controlling $(P=0.019)$, Seeking social support $(P=0.031)$ and Escapeavoidance $(P=0.000)$. Also, they have more expressed level of depressive manifestations $(P=0.000)$.

On the contrary, physicians and nurses with a low degree of burnout appreciate the quality of their lives more and have a greater level of mindfulness - in MAAS scale $(P=0.000)$ and subscales of FFMQ like Non-judging $(P=0.038)$, Nonreactivity $(P=0.004)$, and Observe $(P=0.050)$.

The correlation analysis (Table 3 ) between biomarkers and personality variables showed a positive correlation between symptoms of depression (by BDI) and saliva cortisol ( $\mathrm{r}=0.237, P=0.05)$, DHEA-S ( $\mathrm{r}=0.4, P=0.01$ ), as well as negative correlations between coping Planful problem-solving and the level of melatonin $(\mathrm{r}=-0.232, P=0.05)$, subscales of FFMQ like Describe and the level of DHEA-S ( $\mathrm{r}=-0.304$, $P=0.05)$, Act with awareness and levels of DHEA-S $(\mathrm{r}=-0.238$, $P=0.05)$, salvia cortisol $(\mathrm{r}=-0.207, P=0.05)$ and melatonin $(\mathrm{r}=-$ $0.247, P=0.05$ ).

Multivariate logistic regression analysis (Table 4) was performed to identify predictive factors (independent variables) of burnout (dependent variable). We use all possible predictive factors - psychological (copings, components of mindfulness, depression), demographics (gender, age, religion, marital status, work experience, work hours, and night shifts), and biomarkers (Salivary cortisol, TSH, DHEA-S, Dopamine, Serotonin, Melatonin). The logistic regression model was statistically significant (chi-square $=34.506, P=0.001$ ). The model explained $59 \%$ (Nagelkerke's $\mathrm{R}^{2}$ ) of the variance in exhaustion and classified correctly $74.4 \%$ of the cases. With the increase of confrontation, depression symptoms, and decrease of mindfulness (MAAS scale), the probability of exhaustion increased.

Table 2.

Differences in psychological characteristics between physicians and nurses with a high degree of burnout and those without it

\begin{tabular}{|c|c|c|c|c|c|}
\hline & Scales & M & SD & $\mathrm{t}$ & $\mathrm{P}$ \\
\hline $\mathrm{C}$ & High burnout $(n=42)$ & 9.02 & 2.909 & 2.817 & .006 \\
\hline & Low Burnout $(\mathrm{n}=54)$ & 7.39 & 2.750 & & \\
\hline & High burnout $(n=42)$ & 10.26 & 2.820 & 3.039 & .003 \\
\hline D & Low Burnout $(n=54)$ & 8.31 & 3.324 & & \\
\hline & High burnout $(n=42)$ & 14.33 & 2.515 & 2.384 & .019 \\
\hline I & Low Burnout $(\mathrm{n}=54)$ & 12.59 & 4.178 & & \\
\hline Seeking social & High burnout $(n=42)$ & 12.07 & 2.815 & 2.194 & .031 \\
\hline & Low Burnout $(n=54)$ & 10.78 & 2.905 & & \\
\hline & High burnout $(n=42)$ & 7.21 & 2.170 & .964 & .338 \\
\hline & Low Burnout $(\mathrm{n}=54)$ & 6.76 & 2.387 & & \\
\hline & High burnout $(n=42)$ & 13.14 & 2.951 & 4.525 & .000 \\
\hline & Low Burnout $(\mathrm{n}=54)$ & 9.74 & 4.117 & & \\
\hline & High burnout $(\mathrm{n}=42)$ & 13.07 & 2.840 & .351 & .726 \\
\hline $\begin{array}{l}\text { provinn- } \\
\text { solving }\end{array}$ & Low Burnout $(\mathrm{n}=54)$ & 12.83 & 3.612 & & \\
\hline & High burnout $(n=42)$ & 12.95 & 3.428 & -.735 & .464 \\
\hline & Low Burnout $(\mathrm{n}=54)$ & 13.44 & 3.112 & & \\
\hline & High burnout $(n=42)$ & $70.29 \%$ & $13.31 \%$ & -4.385 & .000 \\
\hline & Low Burnout $(\mathrm{n}=54)$ & $80.81 \%$ & $10.19 \%$ & & \\
\hline BDI & High burnout $(n=42)$ & 11.74 & 7.130 & 4.410 & .000 \\
\hline & Low Burnout $(\mathrm{n}=54)$ & 6.00 & 5.623 & & \\
\hline Describe & High burnout $(n=42)$ & 22.69 & 5.000 & .195 & .846 \\
\hline & Low Burnout $(\mathrm{n}=54)$ & 22.47 & 5.750 & & \\
\hline Non-judging & High burnout $(n=42)$ & 29.55 & 5.886 & -2.109 & .038 \\
\hline & Low Burnout $(\mathrm{n}=54)$ & 31.85 & 4.753 & & \\
\hline Non-reactivity & High burnout $(\mathrm{n}=42)$ & 25.81 & 7.865 & -2.931 & .004 \\
\hline & Low Burnout $(n=54)$ & 29.83 & 5.487 & & \\
\hline Act with & High burnout $(\mathrm{n}=42)$ & 27.60 & 5.623 & -.661 & .510 \\
\hline & Low Burnout $(\mathrm{n}=54)$ & 28.36 & 5.565 & & \\
\hline Observe & High burnout $(\mathrm{n}=42)$ & 20.52 & 3.983 & -1.972 & .050 \\
\hline & Low Burnout $(\mathrm{n}=54)$ & 22.28 & 5.145 & & \\
\hline MAAS & High burnout $(n=42)$ & 62.10 & 8.114 & -4.137 & .000 \\
\hline & Low Burnout $(\mathrm{n}=54)$ & 69.74 & 9.542 & & \\
\hline
\end{tabular}


Table 3.

Pearson correlation between biomarkers and psychological factors $(n=96)$

\begin{tabular}{|l|c|c|c|c|c|c|}
\hline \multicolumn{1}{|c|}{ Variable } & TSH & DHEA-S & $\begin{array}{c}\text { Dopa- } \\
\text { min }\end{array}$ & $\begin{array}{c}\text { Seroto- } \\
\text { nin }\end{array}$ & $\begin{array}{c}\text { Saliva } \\
\text { cortisol }\end{array}$ & $\begin{array}{c}\text { Mela- } \\
\text { tonin }\end{array}$ \\
\hline Confrontive coping & .046 & -.007 & .046 & .015 & .170 & .099 \\
\hline Distancing & .106 & -.039 & .006 &, 200 & .090 & -.005 \\
\hline Self-controlling & .103 & .114 & .015 & .038 & .079 & -.140 \\
\hline Seeking social support & .198 & .054 & .058 & -.004 & .028 & .100 \\
\hline Accepting responsibility & .136 & -.200 & -.019 & .118 & -.053 & -.059 \\
\hline Escape-avoidance & .136 & .140 & .062 & .094 & .116 & .048 \\
\hline Planful problem-solving & .123 & -.072 & -.019 & .190 & .050 & $-.232^{*}$ \\
\hline Positive reappraisal & .060 & -.096 & -.049 & .166 & -.035 & -.204 \\
\hline SF-12 & -.086 & -.200 & -.114 & .030 & -.158 & -.116 \\
\hline BDI & .119 & $.400^{* *}$ & .125 & .103 & $.237^{*}$ & .036 \\
\hline Observe & -.027 & .024 & .040 & -.032 & -.018 & -.121 \\
\hline Describe & .063 & $-.304^{*}$ & -.137 & -.119 & -.092 & -.206 \\
\hline Act with awareness & -.101 & $-.238^{*}$ & .043 & -.001 & $-.207^{*}$ & $-.247^{*}$ \\
\hline Non-judging & -.008 & -.012 & -.196 & -.134 & .037 & .083 \\
\hline Non-reactivity & .099 & -.128 & .020 & .069 & .001 &.- .161 \\
\hline MAAS & -.094 & -.184 & -.091 & -.160 & .001 &.- .148 \\
\hline
\end{tabular}

** Correlation is significant at the 0.01 level (two-tailed)

* Correlation is significant at the 0.05 level (two-tailed)

Table 4

Model of multiple logistic regression

\begin{tabular}{|l|c|c|c|c|c|c|c|c|}
\hline \multirow{2}{*}{ Factors } & B & S.E. & Wald & df & P & OR & \multicolumn{2}{|c|}{$95 \%$ CI } \\
\cline { 7 - 10 } & & & & & & Lower & Upper \\
\hline $\begin{array}{l}\text { Confrontive } \\
\text { coping }\end{array}$ & .287 & .111 & 6.728 & 1 & .009 & 1.333 & 1.073 & 1.655 \\
\hline MAAS & -.071 & .029 & 5.866 & 1 & .015 & .931 & .879 & .986 \\
\hline BDI & .128 & .043 & 8.817 & 1 & .003 & 1.136 & 1.044 & 1.236 \\
\hline
\end{tabular}

\section{Discussion}

The present study about burnout and its relationship with psychological (first of all coping strategies and mindfulness) and socio-demographic factors among physicians and nurses employed in ObGyn is the first large-scale survey in the Siberia region. In the present data, $43.75 \%$ of the physicians and nurses showed a high degree of burnout, which was comparable to that among physicians and nurses in other studies. ${ }^{(2-4)}$

In this study, a higher percentage of physicians and nurses exhibited high scores of EE and DP. These results could be connected with the place of employment and the nature of the job: 24-h work, nightshifts, emergency conditions, COVID-19 pandemic. But we could not find any significant differences between the results of physicians and nurses with a high degree of burnout and those without it in work experience, night shifts, and other factors, which usually are predictors of burnout. We attribute this to the fact that other studies have not taken into account psychological factors, such as coping strategies and mindfulness, which can help (or not) to cope with burnout. Conceivably, these factors allow physicians and nurses to maintain a high level of PA, as shown in our study.

As we mentioned above, there are different opinions about the role of coping and mindfulness in reducing burnout. In one study, ${ }^{(11)}$ it was concluded that coping skills may not mitigate physician EE in some situations; in another the authors concluded that coping is a significant factor in preventing burnout. In this study, we found that not all ways of coping seem to be able to cope with burnout. ${ }^{(24,26)}$

According to the results of logistic regression and comparison of physicians and nurses with a high degree of burnout and those without it, Confrontive coping and, supposedly, coping strategies like Distancing and Escapeavoidance do not discourage but encourage burnout.

Various studies describe maladaptive coping strategies, including Escape-avoidance and similar behavior. ${ }^{(33-35)}$ Susan Folkman and Richard S. Lazarus pointed out that in different situations Confrontive coping and Distancing could be both adaptive and maladaptive. ${ }^{(36)}$ Supposedly, for physicians and nurses employed in ObGyn these coping strategies are maladaptive.

Although some studies show that mindfulness does not help burnout, ${ }^{(24)}$ many others have shown that developing mindfulness prevents burnout. ${ }^{(7,12,13)}$ This disagreement is also shown in our model.

We found significant correlations between some factors of subjective assessment of stress (like coping and mindfulness) and neuroendocrine biomarkers. Although other studies have attempted to connect psychological factors and biomarkers, ${ }^{(15)}$ usually those factors were depression and anxiety. We found that adaptive coping like Planful problem-solving correlated negatively with the level of melatonin, and subscales of the mindfulness questionnaire were correlated negatively with levels of some biomarkers. Thus, we concluded that coping strategies and mindfulness could theoretically contribute to a decrease in the secretion of several hormones. But this assumption requires further confirmation.

We plan to use our results and the regression model to create a program to help physicians and nurses in obstetrics and gynecology reduce burnout.

In conclusion, our results indicate that there are differences in some personality and psychological factors between physicians and nurses in obstetrics and gynecology with a high degree of burnout and those without it. Physicians and nurses with a low degree of burnout have a greater level of mindfulness and a lower level of some maladaptive coping strategies - Confrontive coping, Distancing, Escapeavoidance. Our results focus on the predictive role of these factors of subjective assessment of stress, in particular, Confrontive coping and mindfulness, in burnout syndrome. The present data confirm that there are some psychological and physiological aspects related to stress in the medical 
profession. Indeed, it may be relevant for further research to implement prevention programs aimed at reducing the negative aspects of professional distress and preventing burnout.

This work was performed with the use of equipment of the collective research center "Centre for the development of progressive personalized health technologies" SC FHHRP, Irkutsk

\section{Acknowledgments}

This article contains material that has been discussed at the VIII International Research and Practical Conference «FUNDAMENTAL AND APPLIED ASPECTS OF REPRODUCTION» (December 2021, Irkutsk, Russia). The author thanks all researchers who participated in the oral discussion.

\section{Competing Interests}

The authors declare that they have no competing interests.

\section{References}

1. Maslach C, Jackson SE. The measurement of experienced burnout. Journal of Organizational Behavior. 1981;2:99-113. doi: $10.1002 /$ job.4030020205.

2. Rodrigues H, Cobucci R, Oliveira A, Cabral JV, Medeiros L, Gurgel K, Souza T, Gonçalves AK. Burnout syndrome among medical residents: A systematic review and metaanalysis. PLoS One. 2018 Nov 12;13(11):e0206840. doi: 10.1371/journal.pone. 0206840 .

3. Ofei-Dodoo S, Irwin G, Kuhlmann Z, Kellerman R, WrightHaviland S, Dreiling M. Assessing Work-Related Burnout and Job Satisfaction among Obstetrics and Gynecology Residency Program Coordinators. Kans J Med. 2019 Feb 26;12(1):11-16. 4. Govardhan LM, Pinelli V, Schnatz PF. Burnout, depression and job satisfaction in obstetrics and gynecology residents. Conn Med. 2012 Aug;76(7):389-95.

5. Smith RP. Burnout in Obstetricians and Gynecologists. Clin Obstet Gynecol. 2019 Sep;62(3):405-412. doi: 10.1097/ GRF.0000000000000441.

6. Watanabe N, Horikoshi M, Shinmei I, Oe Y, Narisawa T, Kumachi M, Matsuoka Y, Hamazaki K, Furukawa TA. Brief mindfulness-based stress management program for a better mental state in working populations - Happy Nurse Project: A randomized controlled trial ${ }^{\text {it }}$ tr. J Affect Disord. 2019 May 15;251:186-194. doi: 10.1016/j.jad.2019.03.067.

7. Romani M, Ashkar K. Burnout among physicians. Libyan J Med. 2014 Jan;9(1):23556. doi: 10.3402/ljm.v9.23556.

8. Toker S, Biron M. Job burnout and depression: unraveling their temporal relationship and considering the role of physical activity. J Appl Psychol. 2012 May;97(3):699-710. doi: $10.1037 / \mathrm{a} 0026914$.

9. Gabbe SG, Hagan Vetter M, Nguyen MC, Moffatt-Bruce $\mathrm{S}$, Fowler JM. Changes in the burnout profile of chairs of academic departments of obstetrics and gynecology over the past 15 years. Am J Obstet Gynecol. 2018 Sep;219(3):303.e1303.e6. doi: 10.1016/j.ajog.2018.06.012.
10. Iorga M, Socolov V, Muraru D, Dirtu C, Soponaru C, Ilea C, Socolov DG. Factors Influencing Burnout Syndrome in Obstetrics and Gynecology Physicians. Biomed Res Int. 2017;2017:9318534. doi: 10.1155/2017/9318534.

11. Zivin K, Brower KJ, Sen S, Brownlee RM, Gold KJ. Relationship Between Faculty Characteristics and Emotional Exhaustion in a Large Academic Medical Center. J Occup Environ Med. 2020 Aug;62(8):611-617. doi: 10.1097/ JOM.0000000000001898.

12. Dunne PJ, Lynch J, Prihodova L, O'Leary C, Ghoreyshi A, Basdeo SA, Cox DJ, Breen R, Sheikhi A, Carroll Á, Walsh C, McMahon G, White B. Burnout in the emergency department: Randomized controlled trial of an attention-based training program. J Integr Med. 2019 May;17(3):173-180. doi: 10.1016/j.joim.2019.03.009.

13. Lebares CC, Hershberger AO, Guvva EV, Desai A, Mitchell J, Shen W, Reilly LM, Delucchi KL, O'Sullivan PS, Ascher NL, Harris HW. Feasibility of Formal MindfulnessBased Stress-Resilience Training Among Surgery Interns: A Randomized Clinical Trial. JAMA Surg. 2018 Oct 1;153(10):e182734. doi: 10.1001/jamasurg.2018.2734.

14. Rees C, Craigie M, Slatyer S, Heritage B, Harvey C, Brough P, Hegney D. Mindful Self-Care and Resiliency (MSCR): protocol for a pilot trial of a brief mindfulness intervention to promote occupational resilience in rural general practitioners. BMJ Open. 2018 Jun 30;8(6):e021027. doi: 10.1136/bmjopen-2017-021027.

15. Deneva T, Ianakiev Y, Keskinova D. Burnout Syndrome in Physicians-Psychological Assessment and Biomarker Research. Medicina (Kaunas). 2019 May 24;55(5):209. doi: 10.3390/medicina55050209

16. Kolesnikova LI, Darenskaya MA, Grebenkina LA, Sholokhov LF, Semenova NV, Osipova EV, Kolesnikov SL. [INDICATORS OF PITUITARY-THYROID SYSTEM AND LIPID METABOLISM IN REPRESENTATIVES OF BURYAT ETHNOS AND EUROPEOIDS]. Zh Evol Biokhim Fiziol. 2016 Jul;52(4):270-274. [Article in Russian].

17. Kolesnikova LI, Popova AS, Sinitskiy AI, Kozochkin DA, Gornostaeva AB. [Content of cortisol in cord blood for various impairments of adaptation in newborns]. Vestnik Rossijskoj Akademii Medicinskih Nauk. 2013;68(12):41-43. [Article in Russian].

18. Madaeva IM, Berdina ON, Sholokhov LF, Semenova NV, Kolesnikova LI. Patofiziologicheskie aspekty funktsionirovaniia sistemy neřroéndokrinnoř reguliatsii pri sindrome obstruktivnogo apnoé sna [Pathophysiological aspects of neuro-endocrine regulation system in patients with obstructive sleep apnea syndrome]. Zh Nevrol Psikhiatr Im S S Korsakova. 2018;118(4. Vyp. 2):55-59. doi: 10.17116/ jnevro20181184255. [Article in Russian].

19. Semenova NV, Madaeva IM, Kolesnikova LI. Rol' melatonina kak komponenta antioksidantnor zashchity pri insomnii $\mathrm{v}$ perimenopauze [The role of melatonin as a component of the antioxidant defense system in perimenopausal women with insomnia]. Zh Nevrol Psikhiatr Im S S Korsakova. 2019;119(7):7-13. doi: 10.17116/ jnevro20191190717. [Article in Russian].

20. Tsou MT, Pai TP, Chiang TM, Huang WH, Lin HM, Lee SC. Burnout and metabolic syndrome among different departments of medical center nurses in Taiwan-Crosssectional study and biomarker research. J Occup Health. 2021 Jan;63(1):e12188. doi: 10.1002/1348-9585.12188.

21. Lennartsson AK, Theorell T, Kushnir MM, Jonsdottir 
IH. Changes in DHEA-s levels during the first year of treatment in patients with clinical burnout are related to health development. Biol Psychol. 2016 Oct;120:28-34. doi: 10.1016/j.biopsycho.2016.08.003.

22. Luthar SS, Curlee A, Tye SJ, Engelman JC, Stonnington CM. Fostering Resilience among Mothers under Stress: «Authentic Connections Groups» for Medical Professionals. Womens Health Issues. 2017 May-Jun;27(3):382-390. doi: 10.1016/j.whi.2017.02.007.

23. Danhof-Pont MB, van Veen T, Zitman FG. Biomarkers in burnout: a systematic review. J Psychosom Res. 2011 Jun;70(6):505-24. doi: 10.1016/j.jpsychores.2010.10.012.

24. Banasiewicz J, Zaręba K, Rozenek H, Ciebiera M, Jakiel G, Chylińska J, Owczarek K. Adaptive capacity of midwives participating in pregnancy termination procedures: Polish experience. Health Psychol Open. 2020 Dec 9;7(2):2055102920973229. doi: 10.1177/2055102920973229. 25. O’Dowd E, O'Connor P, Lydon S, Mongan O, Connolly F, Diskin C, McLoughlin A, Rabbitt L, McVicker L, ReidMcDermott B, Byrne D. Stress, coping, and psychological resilience among physicians. BMC Health Serv Res. 2018 Sep 21;18(1):730. doi: 10.1186/s12913-018-3541-8.

26. Winkel AF, Honart AW, Robinson A, Jones AA, Squires A. Thriving in scrubs: a qualitative study of resident resilience. Reprod Health. 2018 Mar 27;15(1):53. doi: 10.1186/s12978018-0489-4.

27. Vodopyanova NE, Starchenkova ES. [Burnout syndrome]. Saint-Petersburg: Peter; 2008. [In Russian].

28. Atalyan AV, Kolesnikova LI, Kolesnikov SI, Grjibovski AM, Suturina LV. Research electronic data capture (redcap) for building and managing databases for populationbased biomedical studies. Human Ecology. 2019; 2. 52-59. doi: 10.33396/1728-0869-2019-2-52-59

29. Vasserman LI, Iovlev BV, Isaeva ER, Trifonova EA., Shchelkova OY. [Methods for psychological diagnosis of coping strategies in stressful and problematic situations for the individual]. Saint-Petersburg: St. Petersburg Psychoneurological Institute named after V. M. Bekhterev; 2008. [In Russian].

30. Baer RA, Smith GT, Lykins E, Button D, Krietemeyer J, Sauer S, Walsh E, Duggan D, Williams JM. Construct validity of the five facet mindfulness questionnaire in meditating and nonmeditating samples. Assessment. 2008 Sep;15(3):329-42. doi: 10.1177/1073191107313003.

31. Carlson LE, Brown KW. Validation of the Mindful Attention Awareness Scale in a cancer population. J Psychosom Res. 2005 Jan;58(1):29-33. doi: 10.1016/j. jpsychores.2004.04.366.

32. De la Fuente-Solana EI, Suleiman-Martos N, PradasHernández L, Gomez-Urquiza JL, Cañadas-De la Fuente GA, Albendín-García L. Prevalence, Related Factors, and Levels of Burnout Syndrome Among Nurses Working in Gynecology and Obstetrics Services: A Systematic Review and Meta-Analysis. Int J Environ Res Public Health. 2019 Jul 19;16(14):2585. doi: 10.3390/ijerph16142585.

33. Białek K, Sadowski M. Level of stress and strategies used to cope with stress by physicians working in intensive care units. Anaesthesiol Intensive Ther. 2019;51(5):361-369. doi: 10.5114/ait.2019.90473.

34. Cullati S, Cheval B, Schmidt RE, Agoritsas T, Chopard P, Courvoisier DS. Self-Rated Health and Sick Leave among Nurses and Physicians: The Role of Regret and Coping Strategies in Difficult Care-Related Situations. Front Psychol. 2017 Apr 20;8:623. doi: 10.3389/fpsyg.2017.00623.

35. Lee-Winn AE, Townsend L, Reinblatt SP, Mendelson T. Associations of neuroticism-impulsivity and coping with binge eating in a nationally representative sample of adolescents in the United States. Eat Behav. 2016 Aug;22:133-140. doi: 10.1016/j.eatbeh.2016.06.009.

36. Stein NL, Leventhal B, Trabasso TR. Psychological and Biological Approaches to Emotion. 1st Edition. New York; 1990. 